\title{
Temperature-Dependent Compressive Deformation Behavior of Commercially Pure Iron Processed by ECAP
}

\author{
Ying Yan $\cdot$ Yue Qi $\cdot$ Qing-Wei Jiang $\cdot$ Xiao-Wu Li
}

Received: 16 August 2014/Revised: 24 October 2014/Published online: 14 February 2015

(C) The Chinese Society for Metals and Springer-Verlag Berlin Heidelberg 2015

\begin{abstract}
To explore the temperature dependence of deformation behavior of BCC structural materials and the relevant effect of pre-annealing, commercially pure iron ( $\mathrm{CP} \mathrm{Fe}$ ) produced by equal-channel angular pressing (ECAP) is selected as the experimental material. The influences of deformation temperature $T$ and pre-annealing on deformation behavior, surface deformation characteristics and substructures of ECAP Fe were systematically studied. The results show that ECAP Fe undergoes a remarkable strain softening stage after a rapid strain hardening during uniaxial compression, and the softening degree and the yield strength $\sigma_{\mathrm{YS}}$ first decrease and then increase with raising temperature. Pre-annealing at $400{ }^{\circ} \mathrm{C}$ effectively weakens the strain softening degree and increases $\sigma_{\mathrm{YS}}$. To understand the influence of deformation temperature on deformation behavior, as well as the relevant pre-annealing effect, deformation and damage characteristics and dislocation structures are studied in detail. In a word, the strain softening of ECAP Fe is associated not only with internal structural instability, but also with temperature, and pre-annealing at $400{ }^{\circ} \mathrm{C}$ improves high-temperature mechanical properties of ECAP Fe.
\end{abstract}

KEY WORDS: ECAP Fe; Uniaxial compression; High-temperature mechanical behavior; Pre-annealing; Deformation features; Microstructure

\section{Introduction}

The effect of grain size refinement on the strengthening of bulk metals has been thoroughly investigated. A linear

Available online at http://link.springer.com/journal/40195

Y. Yan · Y. Qi · Q.-W. Jiang · X.-W. Li ( $₫)$

Institute of Materials Physics and Chemistry, College of

Sciences, Northeastern University, Shenyang 110819, China

e-mail: xwli@mail.neu.edu.cn

Q.-W. Jiang

College of Materials Science and Engineering, Kunming

University of Science and Technology, Kunming 650093, China

X.-W. Li

Key Laboratory for Anisotropy and Texture of Materials,

Ministry of Education, Northeastern University,

Shenyang 110819, China dependence of the yield stress on the inverse of the grain size square root, namely the well-known Hall-Petch relation, was reported [1,2]. A similar equation holds for the flow stress at constant strain [3]. The refinement of grains can increase the strength and concurrently improve the plasticity and toughness of bulk metals. Many mechanical processing techniques have thus been introduced in the preparation of materials to obtain fine grains or ultra-fine grains. The severe plastic deformation (SPD) is one of the most frequently used mechanical processing methods, in particular, equal-channel angular pressing (ECAP) technique. ECAP is an effective method for enhancing the strength of metallic alloys through grain refinement by introducing intensive plastic strain into materials after repetitive pressing. Many studies indicated that the mechanical properties were remarkably improved as pressing pass increased [4-6]. However, the microstructures of finegrained or ultra-fine-grained (UFG) materials produced by 
ECAP have characteristics of cold-worked materials [7] because their microstructures are in a metastable state with limited thermal and mechanical stabilities. Generally, the microstructural stability decreases with increasing pressing pass.

The structural instability is a critical problem for practical engineering applications of structural materials. As loading is exerted to the materials with a metastable microstructure at high temperatures, even at room temperature (RT), the microstructure can be easily changed by dynamic recovery or recrystallization, thus leading to the degeneration of their mechanical properties [8-10]. To enhance the thermal and mechanical stabilities of finegrained or UFG materials and further to improve their comprehensive properties, some investigators have tried to adopt a short-term pre-annealing treatment on such materials [11-15]. For instance, Huang et al. [13] reported an interesting experimental phenomenon that the hardening induced by annealing appeared in a UFG commercially pure (CP) aluminum produced by a SPD technique of accumulative roll bonding (ARB). Similarly, the work by Valiev et al. [15] indicated that controlled annealing could bring about a $30 \%$ increase in strength of nanostructured SPD titanium simultaneously with enhanced ductility as compared to the case of as-produced state. However, some investigations $[10,16,17]$ revealed that the microstructural stability of UFG materials produced by SPD also depended upon their crystalline structures. For example, Jiang et al. [16] compared deformation characteristics and microstructures of UFG $\mathrm{CP} \mathrm{Cu}$ and $\mathrm{Ti}$ at comparative temperatures. They found that small- and large-scale cracks or voids were formed along the shear bands (SBs) on the surface of UFG $\mathrm{Cu}$, whereas only a few fine shear lines and some non-propagation voids appeared on the surface of UFG $\mathrm{Ti}$ at temperatures below recrystallization temperature. As the temperature was above recrystallization temperature, some small cracks (or voids) were observed along grain boundaries (GBs) and slip deformation took place in many coarsened grains for UFG $\mathrm{Cu}$, while only extrusions and intrusions instead of obvious cracks or voids were observable for UFG $\mathrm{Ti}$, and the corresponding microstructures after compressive deformation were different as well. Investigations by Vinogradov et al. [17] also confirmed that UFG CP Ti processed by ECAP exhibited a high thermal stability, and recovery and recrystallization did not take place even as the annealing temperature reached as high as $723 \mathrm{~K}\left(450{ }^{\circ} \mathrm{C}\right)$.

So far, with regard to the studies of the temperature effect on mechanical behavior of UFG materials, the adopted materials basically have face-centered cubic (FCC) and hexagonal close-packed (HCP) structures with commercial purity [8-10, 16-18] due to extensive applications of these two sorts of structural materials in engineering and their notable differences in structural stability. However, there are as yet almost no research findings on the temperature-dependent mechanical behavior of fine-grained or UFG materials with a body-centered cubic (BCC) structure. The materials with BCC structure are one of the important structural materials widely used in engineering as well. The investigations on temperature-dependent deformation behavior of fine-grained materials with BCC structure will provide significant references for their applications in practical engineering. For these reasons, in the present work, $\mathrm{CP}$ Fe with a BCC structure was chosen as the original material, and then pressed by only one pass ECAP, since the increase in ECAP pass will yield more unstable microstructure. The influences of temperature on the compressive deformation behavior, deformation and damage features and microstructures of $\mathrm{CP} F e$ equalchannel angular pressing for one pass, as well as the contribution of pre-annealing to the temperature-dependent deformation behavior, were systematically investigated.

\section{Experimental}

The CP Fe was chosen as the original material, whose chemical composition (wt\%) is: $0.17 \mathrm{Mn}, 0.03 \mathrm{Al}, 0.02 \mathrm{Ni}$, $0.01 \mathrm{Cu}, 0.007 \mathrm{P}, 0.006 \mathrm{~S}, 0.003 \mathrm{C}, 0.0025 \mathrm{Si}$ and balance of Fe. A rod with $10 \mathrm{~mm}$ in diameter and $55 \mathrm{~mm}$ in length was cut from the original $\mathrm{CP}$ Fe billet and then processed by one-pass ECAP using a $90^{\circ}$ die at RT.

To choose suitable pre-annealing temperature, ECAP Fe was pre-annealed at the temperature ranging from 200 to $600{ }^{\circ} \mathrm{C}$, and holding time was chosen as $1 \mathrm{~h}$ to avoid discontinuous recrystallization. The Vickers hardness of pre-

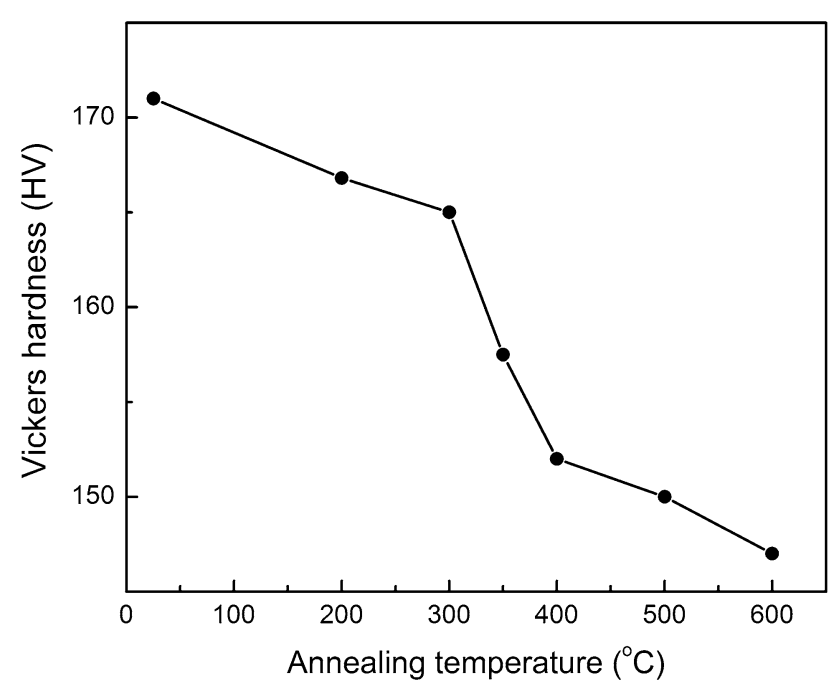

Fig. 1 Variation of Vickers hardness with annealing temperature for ECAP Fe 
annealed specimens was measured using the 450 SVD Vickers Hardness Tester, as indicated in Fig. 1. Apparently, the hardness gradually decreases with increasing temperature, then rapidly reduces at temperatures above $300{ }^{\circ} \mathrm{C}$, and finally slowly drops again above $400^{\circ} \mathrm{C}$, indicating that the recrystallization begins at $300^{\circ} \mathrm{C}$ and finishes above $400{ }^{\circ} \mathrm{C}$. Figure 2 gives the metallographic microstructures of $\mathrm{CPFe}$ and ECAP Fe along the rod axial direction, and both unannealed and pre-annealed at 300 and $400{ }^{\circ} \mathrm{C}$ samples were studied. The coarse equiaxed grains with an average grain size of about $300 \mu \mathrm{m}$ were observed in $\mathrm{CPFe}$ (Fig. 2a), while the elongated grains with $\sim 100 \mu \mathrm{m}$ in length and $\sim 30 \mu \mathrm{m}$ in width were formed in unannealed ECAP Fe (Fig. 2b). There exist some fine recrystallized grain zones at $300{ }^{\circ} \mathrm{C}$ (Fig. 2c), which indicate that the recrystallization has begun, and the growth of recrystallized grains has occurred at $400{ }^{\circ} \mathrm{C}$ (Fig. 2d). Therefore, to achieve a fully recrystallized and relatively homogeneous structure, preannealing temperature of ECAP Fe was chosen as $400{ }^{\circ} \mathrm{C}$, at which the grain sizes range from $\sim 50$ to $250 \mu \mathrm{m}$.

The compressive specimens with a dimension of $3 \mathrm{~mm} \times 3 \mathrm{~mm} \times 5 \mathrm{~mm}$ were cut from the rods of CP Fe and ECAP Fe. Before compression, the specimens were polished electrolytically to obtain a strain-free and clean surface for microscopic observations. The uniaxial compressive tests were conducted to an engineering strain of $45 \%$ along the rod axis using a CMT 5105 (made in China) testing machine with an initial strain rate of $10^{-2} \mathrm{~s}^{-1}$ at RT, 100, 200 and $300{ }^{\circ} \mathrm{C}$, respectively. The surface deformation features and the corresponding substructures after compression were examined carefully by using the SSX-55 scanning electron microscope (SEM) and TECNAI G ${ }^{2} 20$ transmission electron microscope (TEM), respectively.

\section{Results}

\subsection{Stress-Strain Behavior}

Figure 3 displays the true stress-strain curves of $\mathrm{CP}$ Fe and ECAP Fe at various compressive temperatures and a strain rate of $10^{-2} \mathrm{~s}^{-1}$. Apparently, deformation behavior of $\mathrm{CP}$ $\mathrm{Fe}$ is similar to that of conventional-grained materials, namely a sharp strain hardening shortly takes place followed by a slow strain hardening to a final quasi-steady flow state. However, ECAP Fe firstly undergoes a rapid strain hardening and then enters without exception into a remarkable strain softening stage, finally reaches a quasisteady deformation stage with slight hardening. With increasing deformation temperature, the strain softening degree first reduces and then increases. For example, 13.8, $7.2,12.3$ and $16.6 \%$ decreases in stress were measured in the strain softening stage, respectively, at RT, 100, 200 and $300{ }^{\circ} \mathrm{C}$.

To show more clearly the effect of pre-annealing at $400{ }^{\circ} \mathrm{C}$ on the deformation behavior of ECAP Fe, comparisons of the compressive deformation behavior of ECAP $\mathrm{Fe}$ unannealed and pre-annealed at $400{ }^{\circ} \mathrm{C}$ are given in Fig. 4. Two important aspects are worthy to be mentioned. First, the yield strength $\sigma_{\mathrm{YS}}$ for pre-annealed ECAP Fe is higher than that of the unannealed one at the same temperature. Second, pre-annealing effectively weakens the strain softening degree, but the slight strain softening is still observable at high temperatures, e.g., $300{ }^{\circ} \mathrm{C}$, which indicates that the strain softening behavior is not only induced by structural instability, but also related to the deformation temperature.

The variation of $\sigma_{\mathrm{YS}}$ with temperature is revealed in Fig. 5. With raising temperature, there exists a slight decrease in $\sigma_{\mathrm{YS}}$ for $\mathrm{CP} \mathrm{Fe}$; however, for ECAP Fe, the $\sigma_{\mathrm{YS}}$ first rapidly decreases and then increases. After pre-annealing at $400{ }^{\circ} \mathrm{C}$, the $\sigma_{\mathrm{YS}}$ monotonically drops.

On the whole, $\mathrm{CP}$ Fe exhibits a rapid strain hardening followed by a slow hardening to a final quasi-steady flow state, and $\sigma_{\mathrm{YS}}$ slightly decreases with elevating temperature. ECAP Fe undergoes a remarkable strain softening stage after a rapid strain hardening, and the softening degree and $\sigma_{\mathrm{YS}}$ first decrease and then increase as temperature increases. The strain softening phenomena of ECAP Fe pre-annealed at $400{ }^{\circ} \mathrm{C}$ basically disappear, and $\sigma_{\mathrm{YS}}$ monotonically declines with increasing temperature.
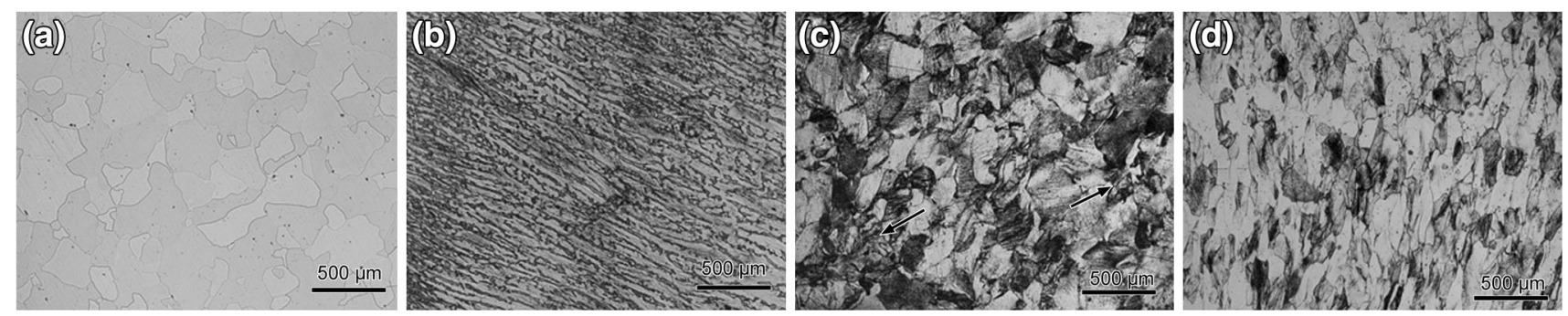

Fig. 2 Metallographs showing the microstructures along the rod axes of CP Fe a and ECAP Fe unannealed $\mathbf{b}$ and pre-annealed at $300{ }^{\circ} \mathrm{C} \mathbf{c}$ and $400{ }^{\circ} \mathrm{C} \mathbf{d}$ for $1 \mathrm{~h}$; arrows in Fig. 2c show the fine recrystallized regions 


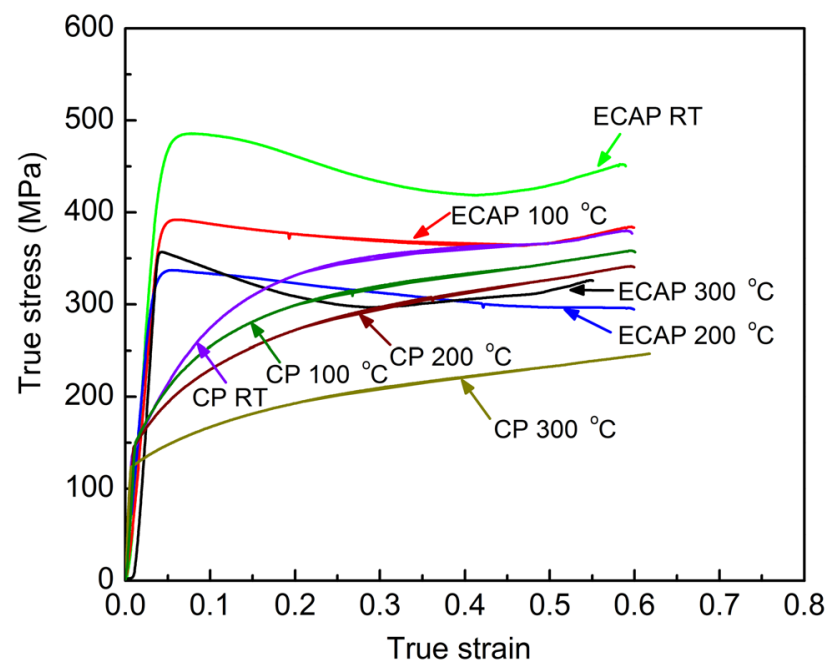

Fig. 3 True stress-strain curves of $\mathrm{CP} F e$ and ECAP Fe compressed at different temperatures and a strain rate of $10^{-2} \mathrm{~s}^{-1}$
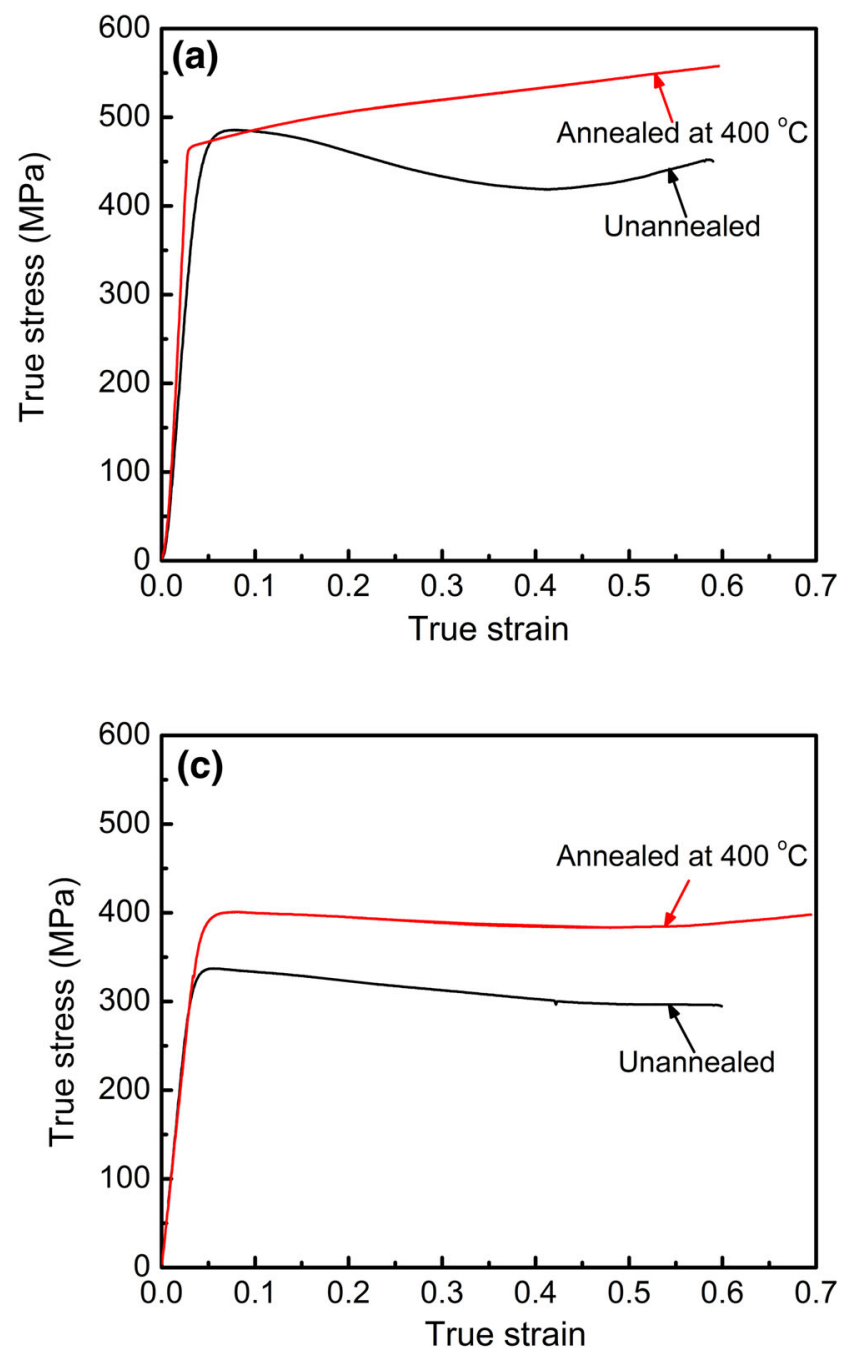

\subsection{Surface Deformation Characteristics}

The surface deformation features of $\mathrm{CP}$ Fe compressed at different temperatures are typically given in Fig. 6. With increasing temperature, the fluctuation degree of surface weakens, and slip lines become clearer; meanwhile, the micro-cracks are initiated at GBs (Fig. 6a-d). As temperature is as high as $300{ }^{\circ} \mathrm{C}$, the unidirectional slip lines become dominated and the cracks propagate not only along GBs but also into grain interiors (Fig. 6e, f).

Figures 7 and 8 show the surface deformation features of ECAP Fe compressed at various temperatures, which are entirely different from those of CP Fe. The large-scale SBs almost appear over the whole surface deformation region at RT (Fig. 7a). With raising temperature, large-scale shear deformation features basically disappear, while the extrusion and intrusion of GBs become more obvious
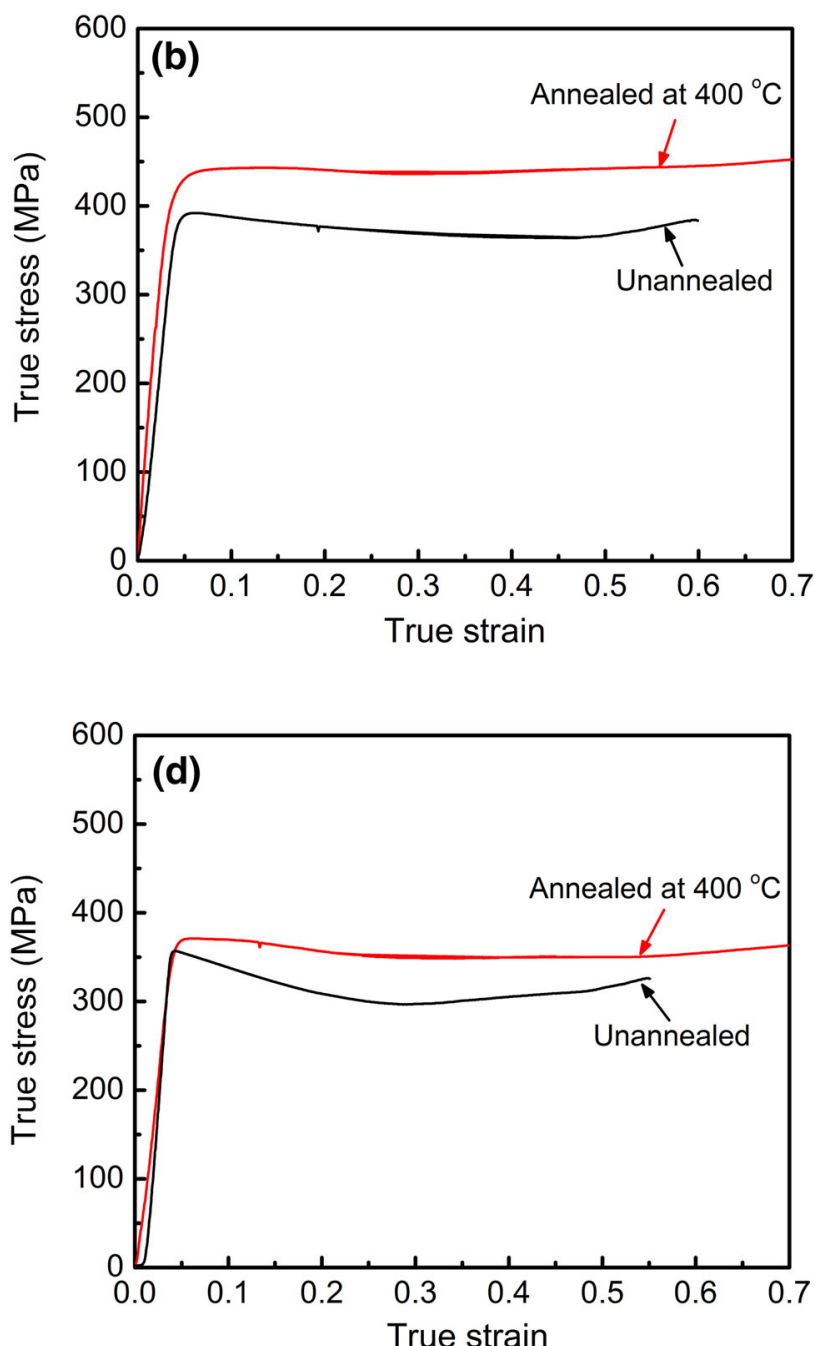

Fig. 4 Comparisons of true stress-strain curves of ECAP Fe unannealed and pre-annealed at $400{ }^{\circ} \mathrm{C}$ at different compressive temperatures and a strain rate of $10^{-2} \mathrm{~s}^{-1}$ : a RT; b $100{ }^{\circ} \mathrm{C}$; c $200{ }^{\circ} \mathrm{C}$; d $300{ }^{\circ} \mathrm{C}$ 


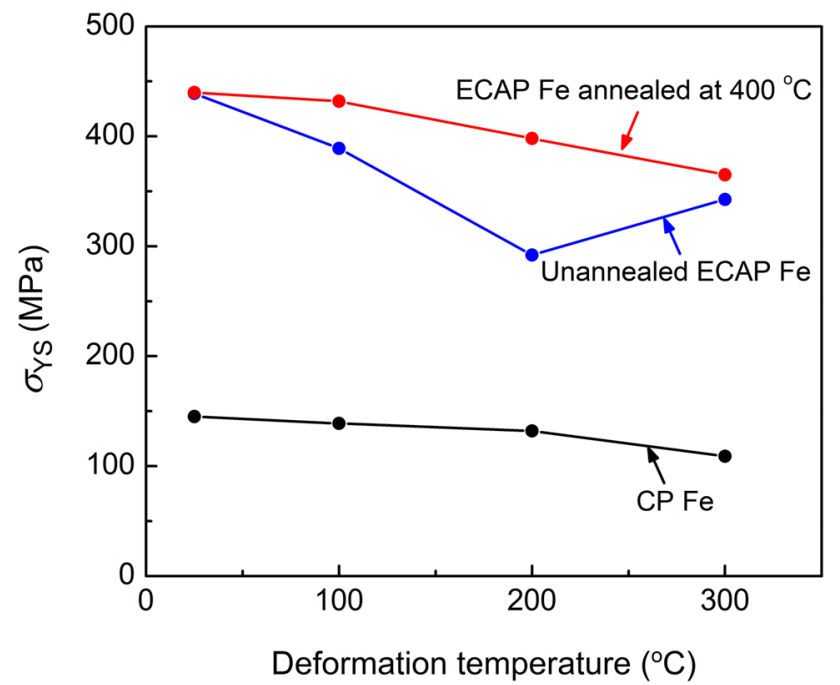

Fig. 5 Variation of $\sigma_{\mathrm{YS}}$ with deformation temperature for $\mathrm{CP} \mathrm{Fe}$ and ECAP Fe unannealed and pre-annealed at $400{ }^{\circ} \mathrm{C}$

(Fig. 7b-d). Further observations reveal that with increasing temperature, the number of primary SBs declines, while secondary SBs become more evident (Fig. 8a, b, d), and the slip lines are observed as well at $200{ }^{\circ} \mathrm{C}$ (Fig. 8e). Meanwhile, the micro-cracks are formed along intersected primary and secondary SBs (Fig. 8c) and at GBs (Fig. 8d). As temperature is raised to $300{ }^{\circ} \mathrm{C}$, almost unidirectional SBs are observed (Fig. 8f).

The surface deformation features of ECAP Fe pre-annealed at $400{ }^{\circ} \mathrm{C}$ are basically the same as those of ECAP
Fe, as shown in Fig. 9, except that the secondary SBs are not so clear (Fig. 9a, b, d, e), and the cracks are only observed along primary SBs (Fig. 9c, f).

In summary, the uniaxial compressive deformation of $\mathrm{CP} \mathrm{Fe}$ is governed by dislocation slip, and the micro-cracks are primarily initiated at GBs. The plastic deformation of ECAP Fe is chiefly dominated by shear deformation, and the dislocation slip becomes enhanced with the increase in temperature. The micro-cracks are formed not only along primary and secondary SBs, but also at GBs for ECAP Fe. A pre-annealing treatment at $400{ }^{\circ} \mathrm{C}$ effectively improves the deformation accommodation between neighboring grains, and the micro-cracks are only formed along primary SBs.

\subsection{Microstructure}

Figure 10 shows TEM images of the microstructures of $\mathrm{CP}$ Fe compressed to an engineering strain amount of $45 \%$ at different temperatures. Dislocation cells and a small amount of sub-grains (SGs) are observed at RT, and the dislocation density in cells is higher (Fig. 10a, b). With increasing $T$, the dislocation density in cells decreases, and the number of SGs increases, but there is no evident change in their sizes (Fig. 10c-f).

TEM images of the microstructures of ECAP Fe unannealed and pre-annealed at $400{ }^{\circ} \mathrm{C}$ before compression are given in Fig. 11. The loose dislocation cells with wider walls along with some lath structures are observed in
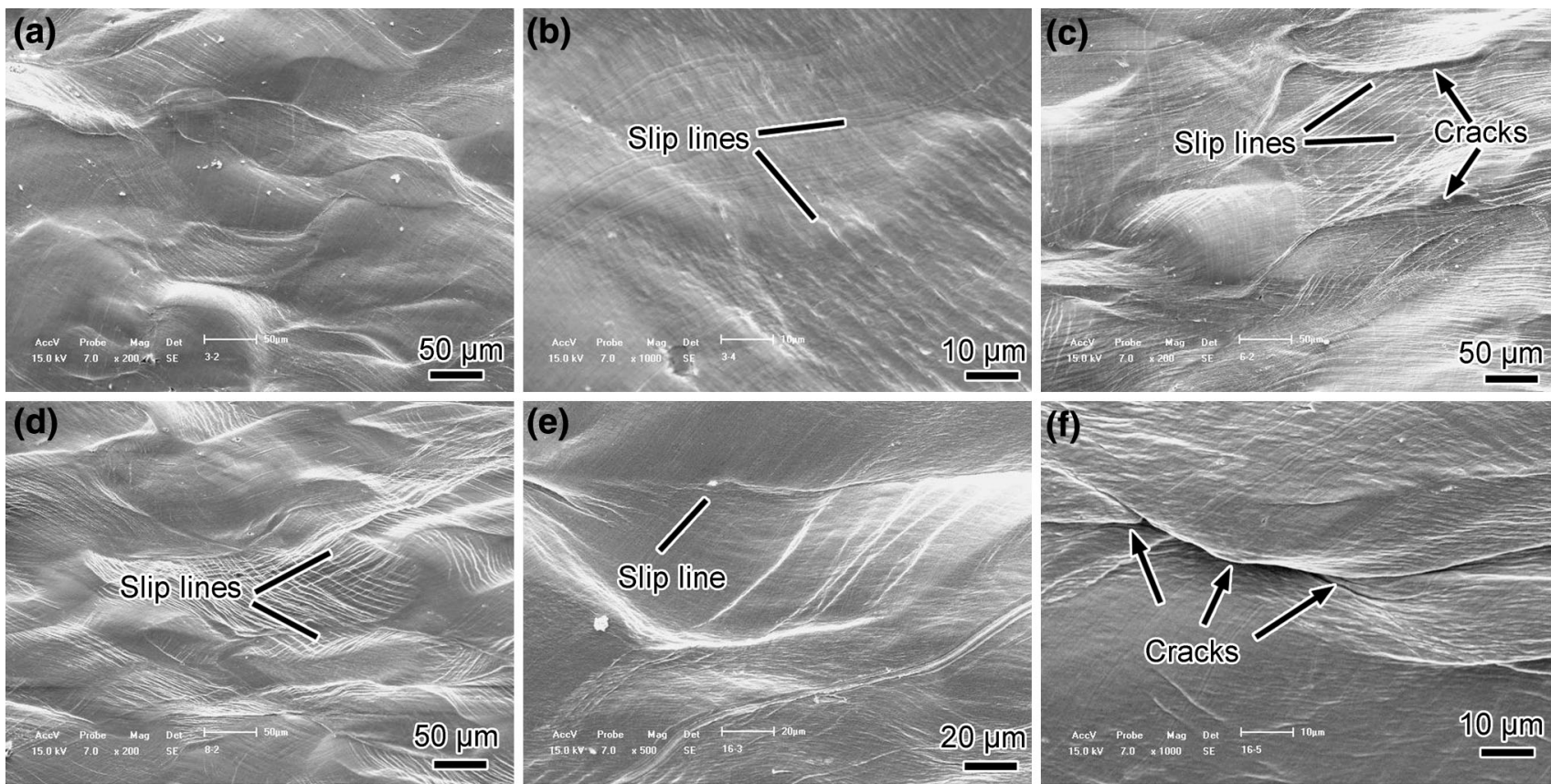

Fig. 6 SEM images of the surface deformation features for CP Fe compressed at different temperatures and a strain rate of $10^{-2} \mathrm{~s}^{-1}: \mathbf{a}, \mathbf{b} \mathrm{RT}$; c $100{ }^{\circ} \mathrm{C} ; \mathbf{d} 200{ }^{\circ} \mathrm{C} ; \mathbf{e}$, f $300{ }^{\circ} \mathrm{C}$ 

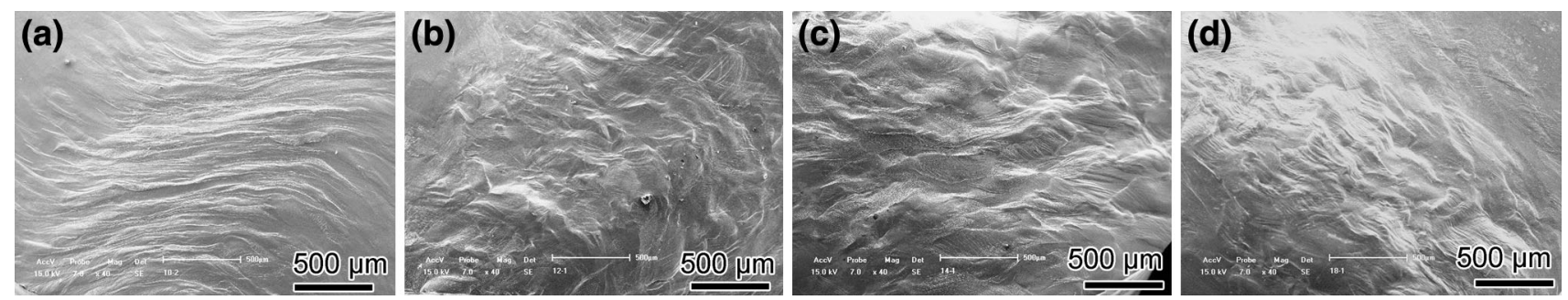

Fig. 7 Low-magnification SEM images of the surface deformation features for ECAP Fe compressed at different temperatures and a strain rate of $10^{-2} \mathrm{~s}^{-1}$ : a RT; b $100{ }^{\circ} \mathrm{C}$; c $200{ }^{\circ} \mathrm{C}$; d $300{ }^{\circ} \mathrm{C}$
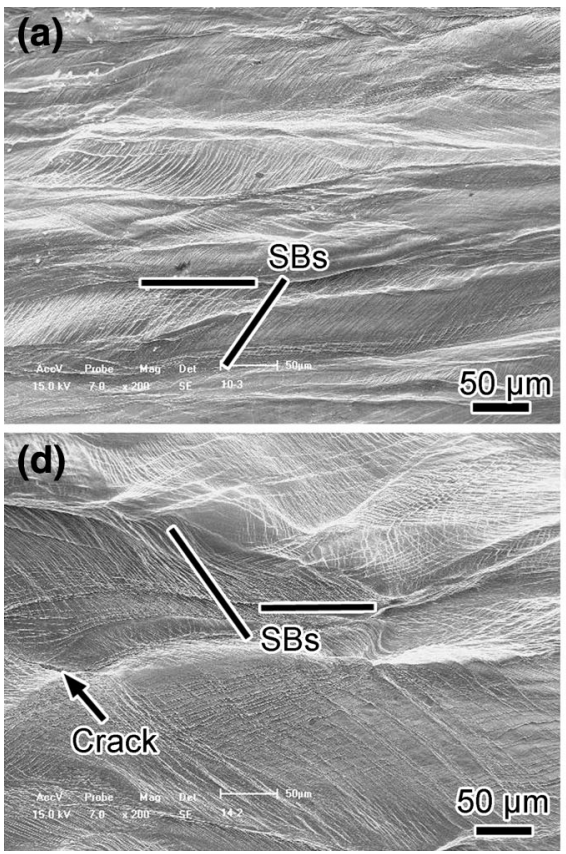
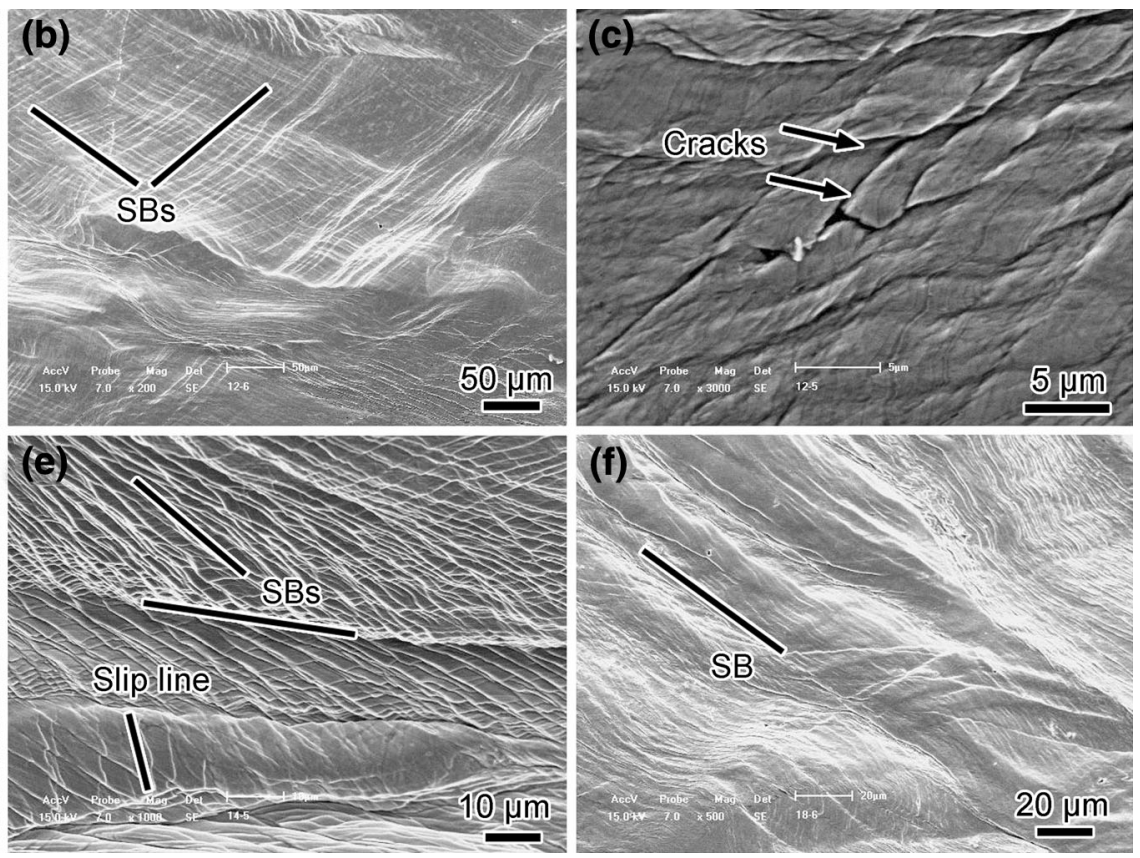

Fig. 8 High-magnification SEM images of the surface deformation features for ECAP Fe compressed at different temperatures and a strain rate of $10^{-2} \mathrm{~s}^{-1}$ : a RT; $\mathbf{b}, \mathbf{c} 100{ }^{\circ} \mathrm{C} ; \mathbf{d}, \mathbf{e} 200{ }^{\circ} \mathrm{C} ; \mathbf{f} 300{ }^{\circ} \mathrm{C}$

ECAP Fe, and the dislocation density in cells and lath structures is higher (Fig. 11a-c). After pre-annealing at $400{ }^{\circ} \mathrm{C}$, a number of SGs, besides fine cells and lath structures, are formed, and there still exist a lot of dislocations in the cells and the laths (Fig. 11d-f).

After the ECAP Fe unannealed and annealed at $400{ }^{\circ} \mathrm{C}$ were compressed to a $45 \%$ engineering strain amount at different temperatures and a strain rate of $10^{-2} \mathrm{~s}^{-1}$, their TEM microstructures are typically given in Figs. 12 and 13, respectively. The dislocation cells with wider walls and some SGs are observed at RT for ECAP Fe (Fig. 12a, b). With raising temperature, the amount and size of SGs and dislocation cells increase (Fig. 12c-e). At $300{ }^{\circ} \mathrm{C}$, lath structures with higher dislocation density are observed (Fig. 12f). In contrast, for ECAP Fe pre-annealed at $400{ }^{\circ} \mathrm{C}$, the dislocation cells are the dominant microstructures at $T \leq 200{ }^{\circ} \mathrm{C}$, and the number of cells with larger size slightly increases and dislocation density in cells decreases (Fig. 13a-d). As temperature is $300{ }^{\circ} \mathrm{C}$, a number of SGs and a small amount of lath structures are formed (Fig. 13e, f).

On the whole, the deformation microstructures of $\mathrm{CPFe}$ are dominated by dislocation cells and a small amount of SGs, and the number of SGs increases with raising temperature. For ECAP Fe, the microstructure change from dislocation cells and SGs at $T \leq 200{ }^{\circ} \mathrm{C}$ to lath structures at $300{ }^{\circ} \mathrm{C}$ occurs, and the amount and size of SGs increase. After pre-annealing at $400{ }^{\circ} \mathrm{C}$, dislocation cells are the dominant microstructures at $T \leq 200{ }^{\circ} \mathrm{C}$, and the size of cells slightly increases with elevating temperature, while a number of SGs and a small amount of lath structures are formed at $300{ }^{\circ} \mathrm{C}$.

\section{Discussion}

Based on the observed results as presented in Figs. 6, 7, 8, 9, 10, 12 and 13, the schematic images are depicted in 

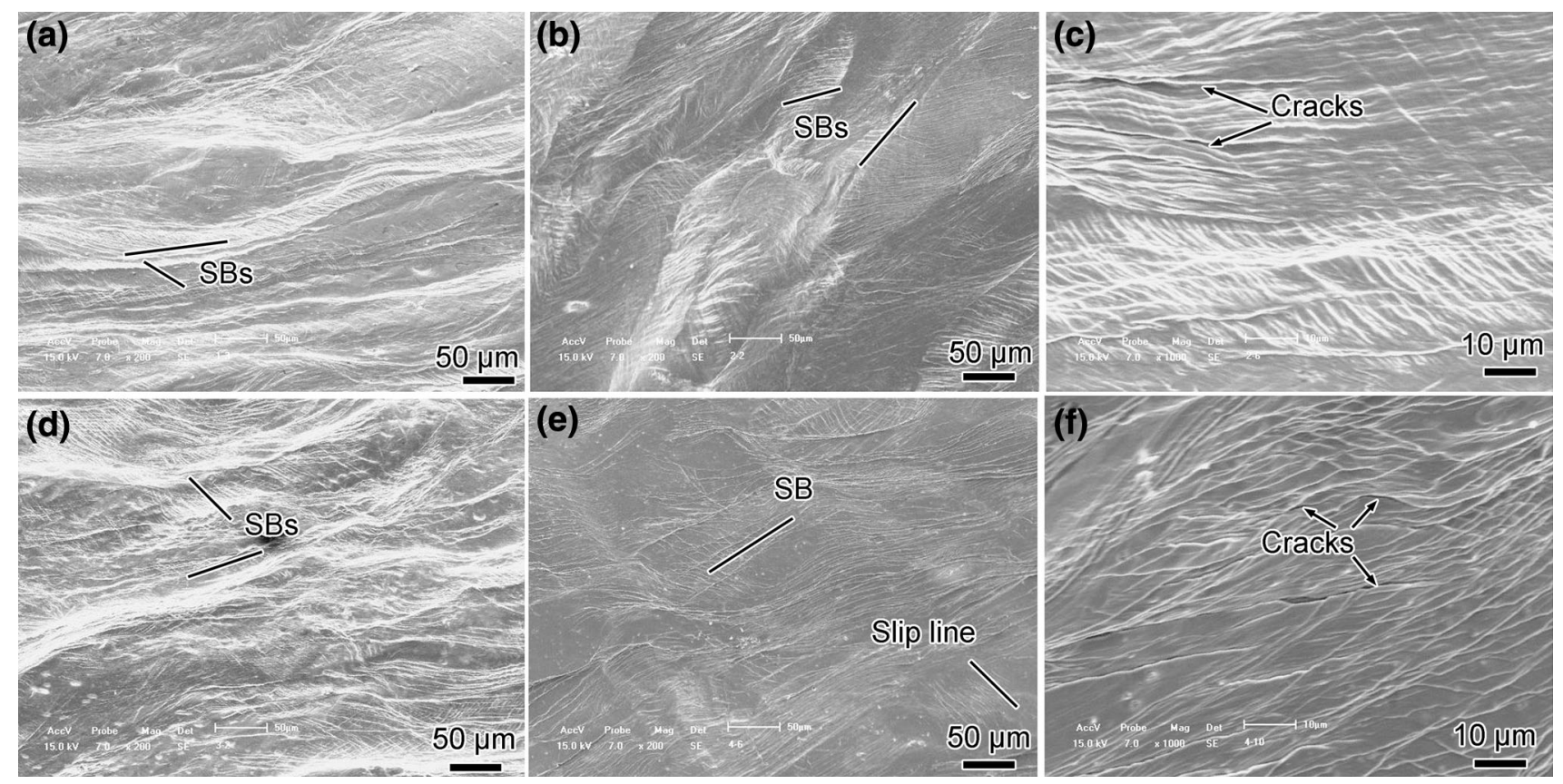

Fig. 9 SEM images of the surface deformation features for ECAP Fe annealed at $400{ }^{\circ} \mathrm{C}$ at different temperatures and a strain rate of $10^{-2} \mathrm{~s}^{-1}$ : a RT; b, c $100{ }^{\circ} \mathrm{C} ; \mathbf{d} 200{ }^{\circ} \mathrm{C} ; \mathbf{e}, \mathbf{f} 300^{\circ} \mathrm{C}$
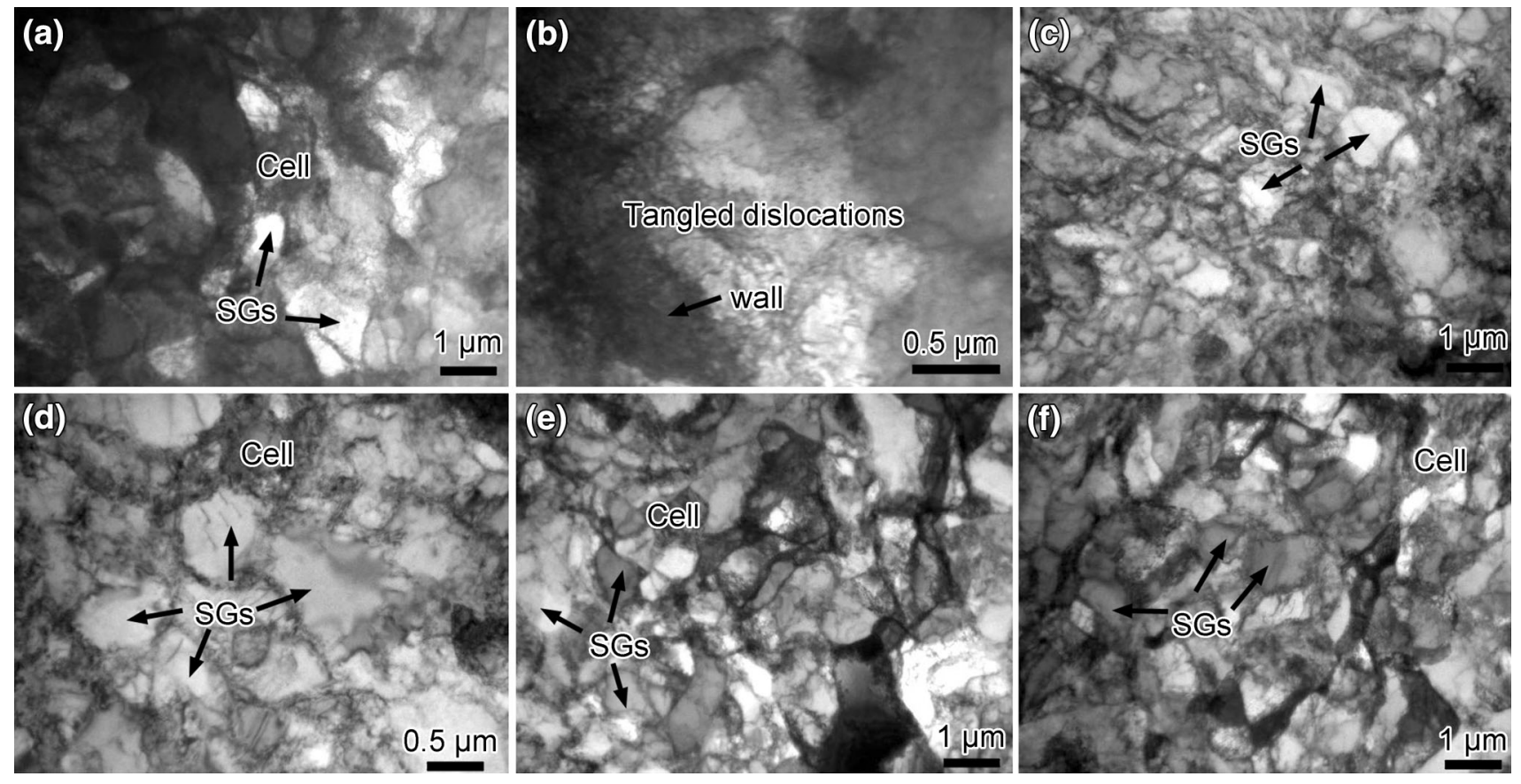

Fig. 10 TEM images of the microstructures of CP Fe compressed to a $45 \%$ strain amount at different temperatures and a strain rate of $10^{-2} \mathrm{~s}^{-1}$ : a, b RT; c, d $100{ }^{\circ} \mathrm{C}$; e $200{ }^{\circ} \mathrm{C}$; f $300{ }^{\circ} \mathrm{C}$

Fig. 14 to show clearly the differences between $\mathrm{CP}$ Fe and ECAP Fe in surface deformation features and substructures after deformation, and the effect of pre-annealing on them. The deformation of $\mathrm{CP} \mathrm{Fe}$ is governed by dislocation slip, and the micro-cracks are initiated at GBs; its substructures are mainly composed of dislocation cells and SGs, and the number of SGs increases with increasing $T$ (Figs. 6, 10 and 14a). The shear deformation dominates the plastic deformation of ECAP Fe unannealed and annealed at $400{ }^{\circ} \mathrm{C}$, and dislocation slip becomes more activated at high 

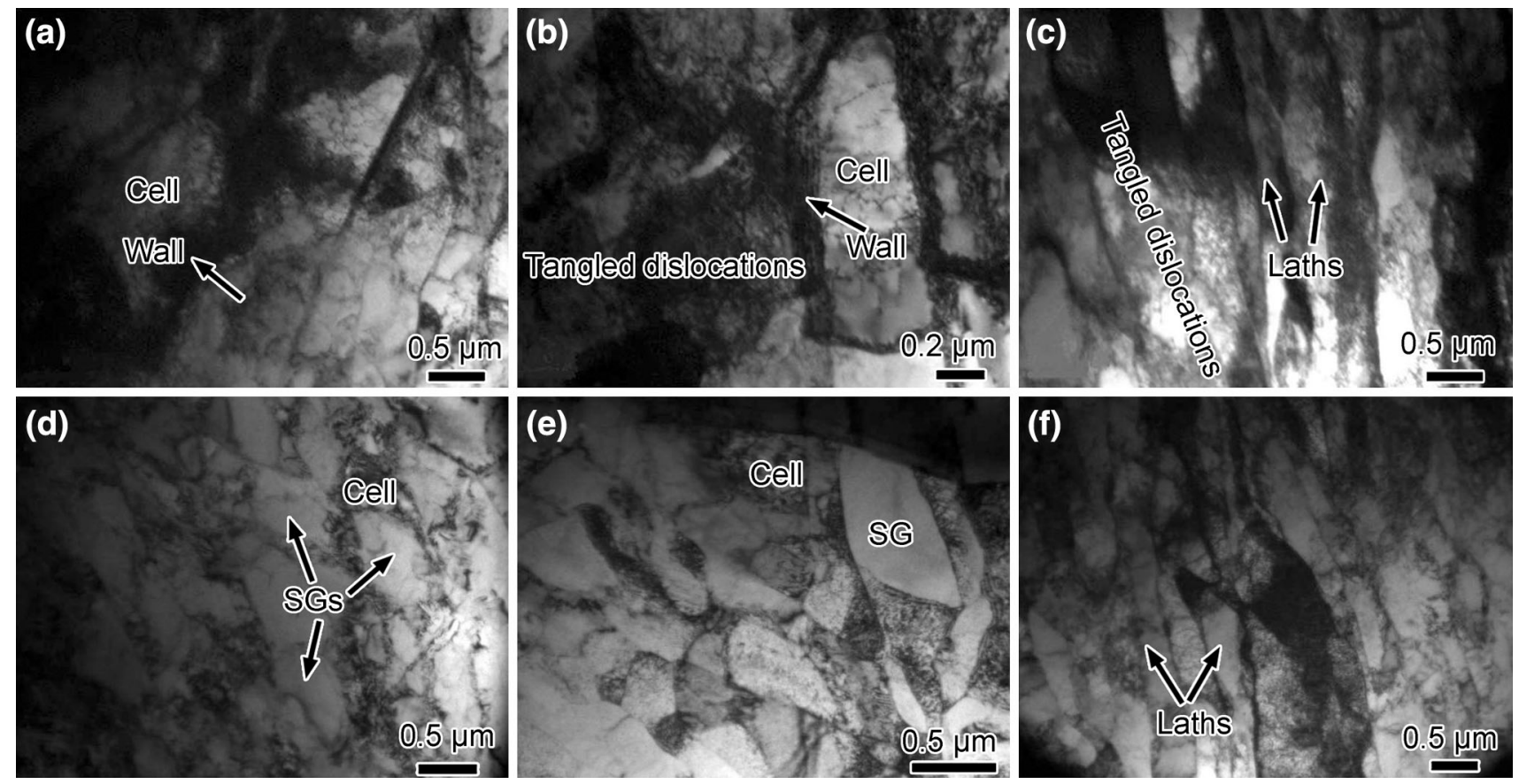

Fig. 11 TEM images of the microstructures of ECAP Fe: a, b, $\mathbf{c}$ unannealed; $\mathbf{d}, \mathbf{e}, \mathbf{f}$ pre-annealed at $400{ }^{\circ} \mathrm{C}$
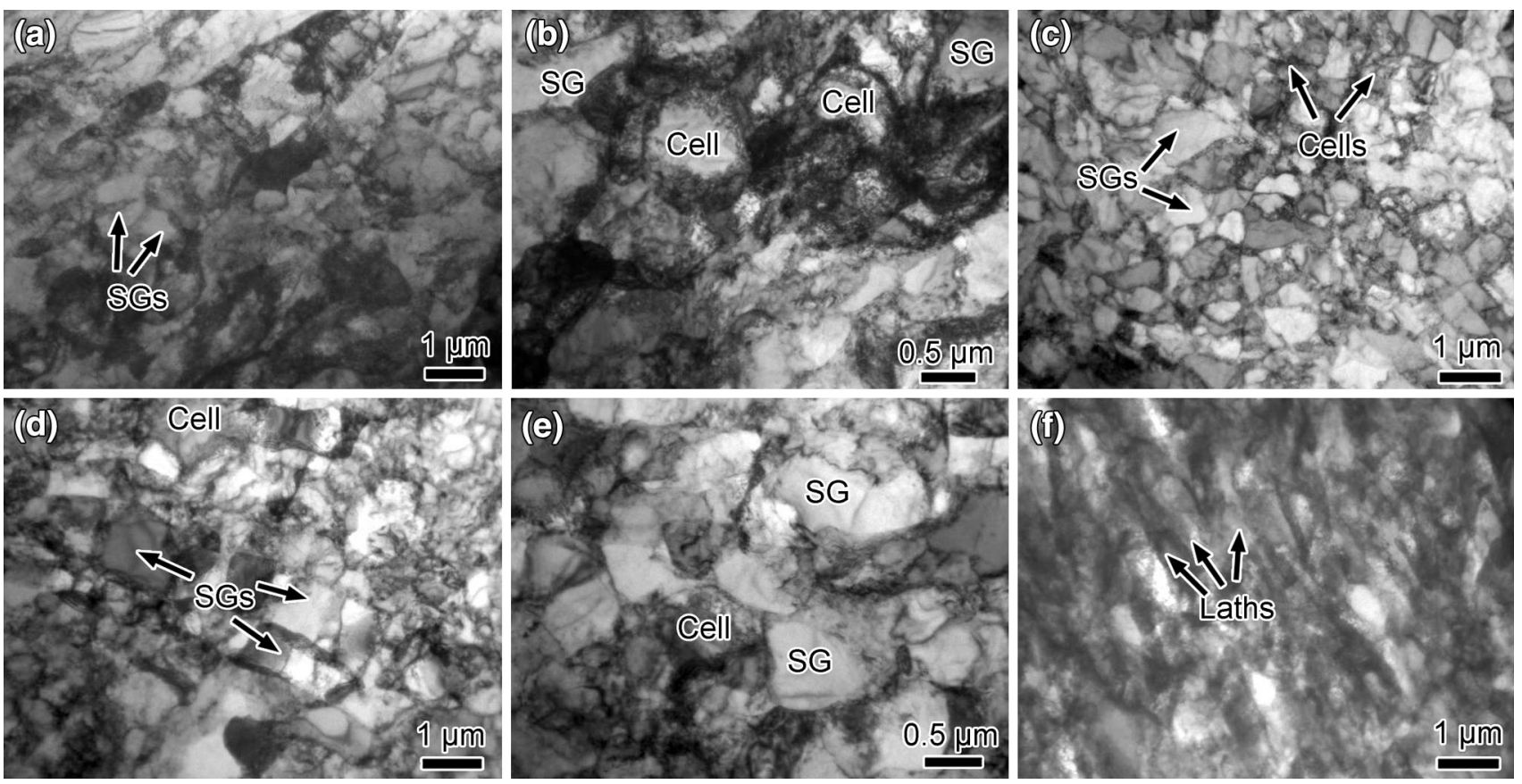

Fig. 12 TEM images of the microstructures of ECAP Fe compressed to a $45 \%$ strain amount at different temperatures and a strain rate of $10^{-2} \mathrm{~s}^{-1}$ : a, b RT; c $100{ }^{\circ} \mathrm{C} ; \mathbf{d}$, e $200{ }^{\circ} \mathrm{C} ; \mathbf{f} 300^{\circ} \mathrm{C}$

temperature; meanwhile, the micro-cracks are formed along primary and secondary SBs or at GBs for ECAP Fe, but only along primary SBs for pre-annealed ECAP Fe (Figs. 8, 9, 14b, c). The substructural change from cells and SGs at $T \leq 200{ }^{\circ} \mathrm{C}$ to laths at $300{ }^{\circ} \mathrm{C}$ occurs for ECAP Fe. After pre-annealing at $400{ }^{\circ} \mathrm{C}$, dislocation cells dominate at $T \leq 200{ }^{\circ} \mathrm{C}$, and a number of SGs and a small amount of laths are formed at $300{ }^{\circ} \mathrm{C}$ (Figs. 12, 13, 14b, c).

According to above experimental results, the temperature-dependent deformation behavior of ECAP Fe and the relevant effect of pre-annealing are discussed in the following Sects. 4.1 and 4.2. 

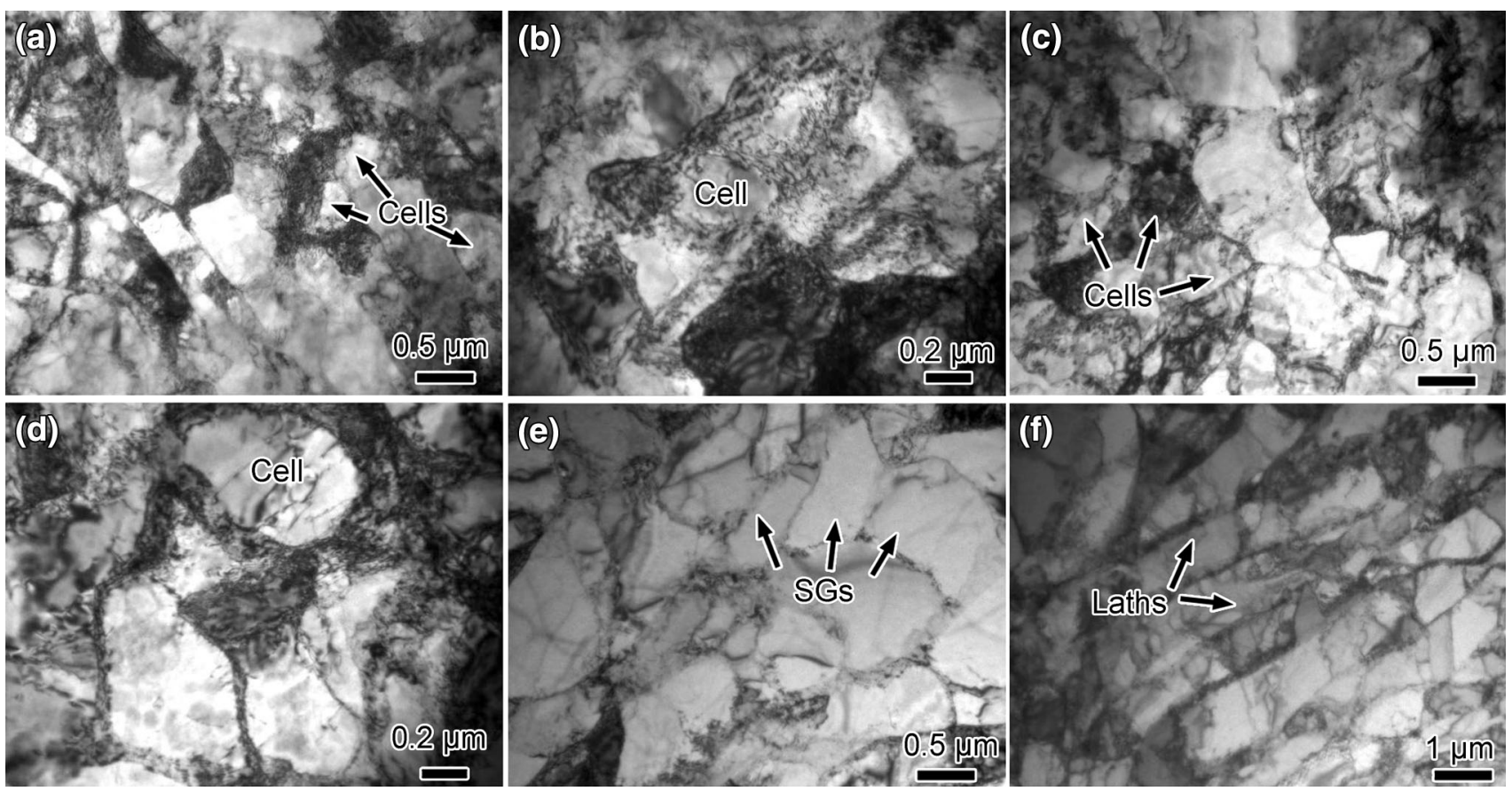

Fig. 13 TEM images of the microstructures of ECAP Fe annealed at $400{ }^{\circ} \mathrm{C}$ compressed to a $45 \%$ strain amount at different temperatures and a strain rate of $10^{-2} \mathrm{~s}^{-1}$ : a, b RT; c $100{ }^{\circ} \mathrm{C} ; \mathbf{d} 200{ }^{\circ} \mathrm{C}$; e, f $300{ }^{\circ} \mathrm{C}$

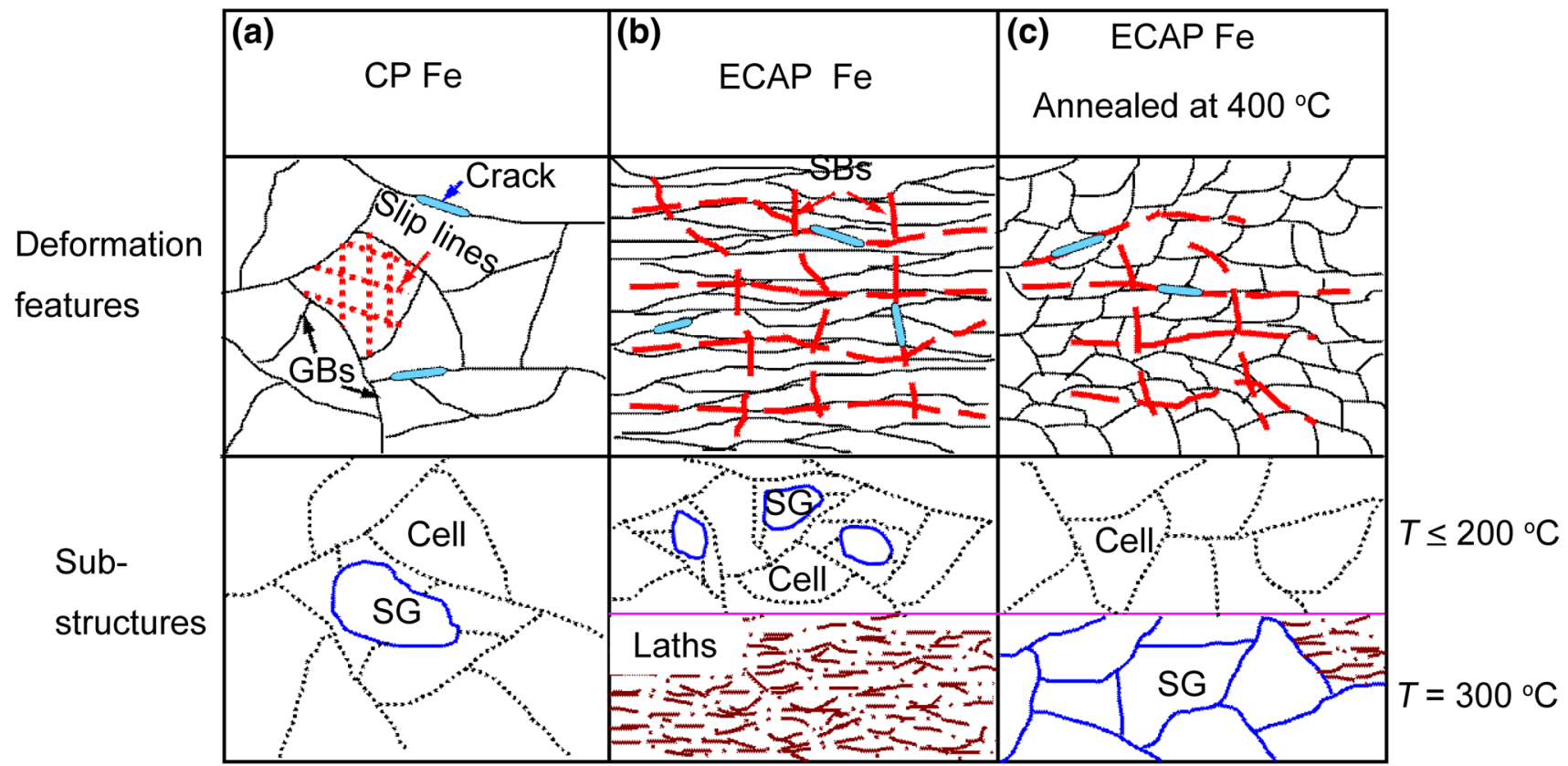

Fig. 14 Schematics of the major differences in deformation features and substructures after compressive deformation among CP Fe (a), the ECAP Fe unannealed (b) and annealed at $400{ }^{\circ} \mathrm{C}$ (c)

\subsection{Temperature Dependence of Deformation Behavior for ECAP Fe}

Some studies $[19,20]$ revealed that dislocations are difficult to generate from the GBs having a non-uniformly distorted dislocation structure. After $\mathrm{CP} F e$ was equalchannel angular pressing, higher dislocation density induced in the cell interiors and walls as well as in lath structures (Fig. 11) prohibits the initiation of dislocation resources, and thus causes the corresponding deformation 
and damage characteristics manifested as the formation of quantities of SBs along with the large-scale SB cracks (Figs. 7, 8 and 14b). Moreover, the fine lamellar microstructure (Fig. 1) notably increases $\sigma_{\mathrm{YS}}$, in comparison with $\mathrm{CP} \mathrm{Fe}$ at the same temperature.

The shear deformation is generally analogous to the dislocation slip. To induce the initial deformation, a certain number of SBs need to be initiated, and the initiated SBs must be able to pass through the impediment of GBs, subGBs or grain interiors. Whether the above two processes can successfully take place determines the initial plastic deformation ability of materials. The strain softening degree in the flow stage depends primarily on the combined influences of the SB initiation and development abilities and the dynamic recovery degree. Figure 8 shows that the SBs, particularly primary $\mathrm{SBs}$, become less as temperature increases due to the enhanced dislocation slip. The similar results were also found in the UFG $\mathrm{Cu}$, in which large-scale SBs cannot be formed at high-temperature cyclic stressing [21].

With increasing temperature, owing to thermal activation of atoms, the decreased number of SBs required to induce the initial deformation, enhanced dislocation mobility (see Fig. 8) and easier GB motion lead to the decrease in $\sigma_{\mathrm{YS}}$. However, the increase in $\sigma_{\mathrm{YS}}$ occurs at $300{ }^{\circ} \mathrm{C}$. This may primarily result from the effect of dynamic recovery, even partial recrystallization (Fig. 2c), which is the same as the strengthening effect produced by short-term pre-annealing $[13,15]$. In addition, the re-pinning of dislocations by the Cottrell atmosphere may also take effect to a certain degree. The dislocations had broken away from the pinning of solute atoms (mainly carbon) as $\mathrm{CP}$ Fe was equal-channel angular pressing. During subsequent compression, these solute atoms will diffuse back to the dislocations again at an appropriate temperature, e.g., $300{ }^{\circ} \mathrm{C}$, forming the atmosphere. Similar phenomenon was often experimentally observed in some steels and HCP materials at a certain temperature $[10,22]$.

The tendency for the variation in strain softening degree is the same as that of $\sigma_{\mathrm{YS}}$. The initiation and propagation of SBs becomes more and more difficult as temperature elevates, which will decrease the strain softening degree. With continuously elevating temperature, the enhanced activation of dislocation slip promotes the dynamic recovery, thus increasing the strain softening degree. Particularly at $300{ }^{\circ} \mathrm{C}$, the elongated SGs form along a certain direction in the late stage of deformation (Figs. 12 and 14b); in this case, the intense dynamic recovery has occurred, and the flow stress is thus largely decreased.

\subsection{Influence of Pre-Annealing on Deformation Behavior of ECAP Fe}

The recrystallization and subsequent grain growth have occurred after ECAP Fe was pre-annealed at $400{ }^{\circ} \mathrm{C}$
(Fig. 2). Although the growth of grains will promote the occurrence of dislocation slip [16], the remaining of lath structures produced during ECAP processing, as well as a lot of dislocations in the cells and the laths (Fig. 11d-f), still leads to the occurrence of shear deformation, but secondary shear bands are not well developed.

The release of elastic strain energy after pre-annealing makes the initiation and propagation of SBs become more difficult, thus increasing $\sigma_{\mathrm{YS}}$ in comparison with the case of ECAP Fe at the same temperature. The decreased number of SBs and the further enhancement of dislocation slip and GB motion result in the monotonic decrease in $\sigma_{\mathrm{YS}}$ as temperature increases. The release of elastic strain energy weakens or delays dynamic recovery during deformation, as displayed in Figs. 13 and $14 \mathrm{c}$ showing that the substructure consists primarily of dislocation cells at $T \leq 200{ }^{\circ} \mathrm{C}$. In addition, the initiation and propagation of SBs become more difficult. Thus, the softening degree is noticeably weakened. While at $300{ }^{\circ} \mathrm{C}$, the slight strain softening is still observable as a result of the occurrence of dynamic recovery, as shown in Figs. 13 and 14c, a number of SGs are formed; however, compared to ECAP Fe, the softening degree is weaker due to more difficult initiation and propagation of SBs.

Almost equiaxed grains in pre-annealed ECAP Fe can well accommodate the deformation between neighboring grains, and secondary SBs are not well developed; thus, the observed micro-cracks only appear along primary SBs. In contrast, for ECAP Fe, the micro-cracks are found at GBs, as well as along primary and secondary SBs.

\section{Conclusions}

(1) ECAP Fe undergoes a remarkable strain softening stage after a rapid strain hardening under uniaxial compression, and the strain softening degree and $\sigma_{\mathrm{YS}}$ first decrease and then increase with elevating temperature in the range from RT to $300{ }^{\circ} \mathrm{C}$. Pre-annealing at $400{ }^{\circ} \mathrm{C}$ effectively weakens the strain softening degree and increases $\sigma_{\mathrm{YS}}$.

(2) The shear deformation dominates the plastic deformation of ECAP Fe, and dislocation slip becomes enhanced with increasing temperature. The microcracks are formed along SBs or at GBs for ECAP Fe, but only along primary SBs after pre-annealing at $400{ }^{\circ} \mathrm{C}$.

(3) Pre-annealing at $400{ }^{\circ} \mathrm{C}$ promotes the formation of fine cells and laths and the development of substructures from loose dislocation cells and laths in ECAP $\mathrm{Fe}$ into a number of SGs. With increasing $T$, the microstructural variation from the cells and SGs at $T \leq 200{ }^{\circ} \mathrm{C}$ to the laths at $300{ }^{\circ} \mathrm{C}$ occurs for ECAP 
$\mathrm{Fe}$, while for ECAP Fe pre-annealed at $400{ }^{\circ} \mathrm{C}$, the cells become dominant microstructures at $T \leq 200{ }^{\circ} \mathrm{C}$, and a number of SGs and a small amount of laths are formed at $300{ }^{\circ} \mathrm{C}$.

Acknowledgments This work was financially supported by the National Natural Science Foundation of China (Nos. 51231002, 51271054, 51201077 and 50671023), the Specialized Research Fund for the Doctoral Program of Higher Education of China (No. 20110042110017) and the Fundamental Research Funds for the Central Universities of China (Nos. N110105001 and N120505001). Thanks also go to Prof. Z.F. Zhang and Dr. Z.J. Zhang for their assistance in the preparation of one pass equal-channel angular pressing Fe samples.

\section{References}

[1] E.O. Hall, Proc. Phys. Soc. B 64, 747 (1951)

[2] N.J. Petch, J Iron Steel Inst 174, 25 (1953)

[3] R. Armstrong, I. Codd, R.M. Douthwaite, N.J. Petch, Philos. Mag. 7, 45 (1962)

[4] D.R. Fang, Z.F. Zhang, S.D. Wu, C.X. Huang, H. Zhang, N.Q. Zhao, J.J. Li, Mater. Sci. Eng. A 426, 305 (2006)

[5] B. Chen, D.L. Lin, L. Jin, X.Q. Zeng, C. Lu, Mater. Sci. Eng., A 483-484, 113 (2008)
[6] E.A. EI-Danaf, Mater. Sci. Eng. A 487, 189 (2008)

[7] X. Molodova, G. Gottstein, M. Winning, R.J. Hellmig, Mater. Sci. Eng. A 460-461, 204 (2007)

[8] X.W. Li, Y. Umakoshi, S.D. Wu, Z.G. Wang, I.V. Alexandrov, R.Z. Valiev, Phys. Status Solidi A 201, R119 (2004)

[9] Z.Y. Yu, Q.W. Jiang, X.W. Li, Phys. Status Solidi A 205, 2417 (2008)

[10] F.W. Long, Q.W. Jiang, L. Xiao, X.W. Li, Mater. Trans. 52, 1617 (2011)

[11] H. Mughrabi, H.W. Höppel, M. Kautz, R.Z. Valiev, Z Metall. 94, 1079 (2003)

[12] N. Kamikawa, X.X. Huang, N. Tsuji, N. Hansen, Acta Mater. 57, 4198 (2009)

[13] X.X. Huang, N. Hansen, N. Tsuji, Science 312, 249 (2006)

[14] W.Z. Han, S.D. Wu, S.X. Li, Y.D. Wang, Mater. Sci. Eng. A 483-484, 430 (2008)

[15] R.Z. Valiev, A.V. Sergueeva, A.K. Mukherjee, Scr. Mater. 49, 669 (2003)

[16] Q.W. Jiang, L. Xiao, X.W. Li, Mater. Sci. Forum 682, 41 (2011)

[17] A.Y. Vinogradov, V.V. Stolyarov, S. Hashimoto, R.Z. Valiev, Mater. Sci. Eng. A 318, 163 (2001)

[18] Q.W. Jiang, X.W. Li, Mater. Sci. Eng. A 546, 59 (2012)

[19] R.Z. Valiev, E.V. Kozlov, Y.F. Ivanov, J. Lian, A.A. Nazarov, B. Baudelet, Acta Metall. Mater. 42, 2467 (1994)

[20] R.Z. Valiev, Mater. Sci. Eng. A 234-236, 59 (1997)

[21] X.W. Li, S.D. Wu, Y. Wu, H.Y. Yasuda, Y. Umakoshi, Mater. Trans. 46, 3077 (2005)

[22] I.E. Dolzhenkov, Met. Sci. Heat Treat. 13, 220 (1971) 